\title{
Putative probiotic Lactobacillus spp. from porcine gastrointestinal tract inhibit transmissible gastroenteritis coronavirus and enteric bacterial pathogens
}

\author{
Rejish Kumar V. J • Byeong Joo Seo • Mi Ran Mun • \\ Chul-Joong Kim • Insun Lee • Hongik Kim • \\ Yong-Ha Park
}

Accepted: 27 June 2010 /Published online: 10 July 2010

(C) Springer Science+Business Media B.V. 2010

\begin{abstract}
A total of 310 bacterial strains isolated from the porcine gastrointestinal tract were tested for their activity against transmissible gastroenteritis (TGE) coronavirus and other enteric pathogens. Based on activity, the strains Probio-38 and Probio-37 were selected as potential probiotics and identified as Lactobacillus plantarum Probio-38 and Lactobacillus salivarius Probio-37 respectively by $16 \mathrm{~S}$ rRNA gene sequencing. Supernatants of these strains inhibited TGE coronavirus in vitro in ST cells, without any cytopathic effect even after $72 \mathrm{~h}$ of incubation. Both the strains exhibited high survival in synthetic gastric juice. The strains were resistant to $5 \%$ porcine bile and exhibited antimicrobial activity against all the 13 enteric bacterial pathogens tested. These strains also exhibited resistance to most of the antibiotics analyzed. The inhibition of transmissible gastroenteritis coronavirus and enteric bacterial pathogens as well as the bile tolerance, high survival in gastric juice, and the antibiotic resistance indicate that the two isolated bacterial strains are ideal probiotic candidates for animal application after proper in vivo experiments.
\end{abstract}

R. K. V. J・B. J. Seo • M. R. Mun • I. Lee · H. Kim •

Y.-H. Park $(\bowtie)$

Department of Applied Microbiology and Biotechnology,

Yeungnam University,

Kyongsan,

Kyeongbuk 712-749, South Korea

e-mail: peter@ynu.ac.kr

C.-J. Kim

Collage of Veterinary Medicine,

Chungnam National University,

Daejeon 305-764, South Korea
Keywords Transmissible gastroenteritis coronavirus . Lactobacillus plantarum . Lactobacillus salivarius. Enteric pathogens $\cdot$ Antibiotic sensitivity

\section{Introduction}

Enteric diseases are common problem in modern pig production worldwide. Several agents including viruses, bacteria, and protozoans have been suggested as possible causes of diarrhea in growing pigs (Jacobson et al. 2003). Among these, transmissible gastroenteritis (TGE) caused by coronavirus is a highly contagious enteric disease resulting in a mortality of nearly $100 \%$ (Pritchard 1987). It is a major cause of viral enteritis and fetal diarrhea in swine; it is most severe in neonates, with mortality resulting in significant economic loss (Enjuanes et al. 1995). TGE virus is a member of the Coronaviridae family of the order Nidovirales (Cavanagh et al. 1997). TGEV replicates in both the villous epithelial cells of the small intestine and in the lung cells of newborn piglets (Enjuanes and Van der Zeijst 1995). Enteric bacterial infections are also among the most common and economically significant diseases affecting swine production with clinical signs of diarrhea, reduced growth rate, weight loss, and death of preweaned, weanling, grower finisher, and young and adult age breeding animals (Moxley and Duhamel 1999).

Lactobacillus species have been widely used in both humans and animals to prevent or treat gastrointestinal disorders (Drago et al. 1997; Ouwehand et al. 2004). Lactic acid bacteria produce lactic acid, which lowers the $\mathrm{pH}$ of the intestinal content and helps to inhibit the development 
of invasive pathogens such as Salmonella spp. or strains of Escherichia coli. Lactobacillus species are reported to have beneficial effects in the gastrointestinal tract in experimental rats (Mangell et al. 2002). Weaned piglets fed with diet supplements of different lactic acid bacteria (LAB) complexes, comprising combinations of Enterococcus faecium 6H2, Lactobacillus acidophilus C3, Pediococcus pentosaceus D7, Lactobacillus plantarum $1 \mathrm{~K} 8$, and L. plantarum $3 \mathrm{~K} 2$ were less affected by diarrhea than piglets fed the control diet, suggesting that the LAB complexes tested have probiotic properties in weaned piglets (Giang et al. 2010). Besides its antibacterial activity, many researchers reported the antiviral activity of Lactobacillus species against different human and animal viruses. Studies found that $L$. acidophilus has significant immunopotentiating effects and recommended for use as safe oral adjuvant for rotavirus vaccines in pigs (Van Niel et al. 2002; Zhang et al. 2008). Oral administration of Lactobacillus assists vaccination efficiency against porcine reproductive and respiratory syndrome virus (PRRSV) and also provides higher bodyweight gain following PRRS infection (Kritas and Morrison 2007). In the present study, we screened 310 bacterial isolates from porcine gastrointestinal tract against TGE coronavirus and enteric bacterial pathogens to select the potent probiotic species.

\section{Materials and methods}

\section{Isolation and culture conditions}

Fresh samples of stomach, small intestinec and large intestine were collected immediately from a healthy pig after slaughter at a commercial pig processing plant in Daejeon, Korea. Samples were collected into an anaerobic bag (BBL, Cockeysville, MD, USA), kept on ice, and immediately transferred to an anaerobic chamber (Sheldon Manufacturing, Cornelius, OR, USA) under $85 \% \mathrm{~N}_{2}, 10 \%$ $\mathrm{H}_{2}$, and $5 \% \mathrm{CO}_{2}$, and the remaining samples were stored at $-70^{\circ} \mathrm{C}$ for further study. Thirty grams of each sample was diluted to $1: 10$ in an anaerobic diluent $(0.78 \%$ $\mathrm{K}_{2} \mathrm{HPO}_{4}$ salt mixed with $37.5-\mathrm{mL}$ solution of L-cystein $0.5 \mathrm{~g}, 25 \% \mathrm{~L}$-ascorbic acid $2 \mathrm{~mL}, 8 \% \mathrm{Na}_{2} \mathrm{CO}_{3} 50 \mathrm{~mL}$, and $0.1 \%$ resazurin $1 \mathrm{~mL}$, in $860 \mathrm{~mL}$ sterile distilled water containing $0.5 \mathrm{~g}$ agar). The solution was then kept on a rotary shaker at $100 \mathrm{rpm}$ for $2 \mathrm{~h}$. The $\mathrm{pH}$ of the solution was adjusted to 2 . After $2 \mathrm{~h}$ of shaking, $1 \mathrm{~mL}$ of the dilution was spread over a BL (glucose blood liver) agar medium containing $2 \%$ of dehydrated fresh bile (Oxgall, Difco Laboratories, Detroit, MI, USA) and incubated at $37^{\circ} \mathrm{C}$ for $48 \mathrm{~h}$. Three hundred ten bacterial colonies from the $\mathrm{BL}$ agar plates were then inoculated into MRS broth (Difco Laboratories) and stored at $-80^{\circ} \mathrm{C}$ in $10 \%(w / v)$ skim milk (Difco Laboratories) for screening against enteric pathogens and transmissible gastroenteritis coronavirus. The selected strains were observed for cell morphology and physiology and identified by $16 \mathrm{Sr}$ RNA gene amplification using universal primers and sequencing (Yoon et al. 1998).

\section{Antiviral assay}

TGE corona virus obtained from National Veterinary Research and Quarantine Service, Republic of Korea was used for the study. Bacterial isolates were tested for TGE corona virus inhibition in vitro in ST cells. Viral inoculum was prepared as follows: The virus suspension was allowed to adsorb for $30 \mathrm{~min}$ onto a monolayer of ST cells washed twice with phosphate-buffered saline (PBS). The cells were incubated in serum-free minimal essential medium Eagle (MEM) at $37^{\circ} \mathrm{C}$ in a humidified chamber with $5 \% \mathrm{CO}_{2}$ until there is cytopathic effect (CPE) in $70 \%$ of the cells. The cells along with the medium were frozen and thawed twice, and centrifuged at 1,500 rpm for $5 \mathrm{~min}$, and the supernatant was stored at $-70^{\circ} \mathrm{C}$ until use. This supernatant was used for the estimation of viral titer in 96well microplate cultures of ST cells. Ten-fold serial dilutions of the viral inoculum were prepared, and each dilution was inoculated into 10 wells. Control wells devoid of the inoculum were also maintained. After 72 h, CPE was observed (Fig. 1) and tissue culture infectious dose, $\mathrm{TCID}_{50} / \mathrm{mL}$, was calculated according to the method of Reed and Muench (1938). For the antiviral assay, bacterial supernatant was prepared from 24-h-old culture of bacterial isolates grown in MRS medium. Supernatant collected by centrifugation at $15,000 \mathrm{rpm}$ for 5 min was incubated at $70^{\circ} \mathrm{C}$ for $5 \mathrm{~min}$ and filter-sterilized using cellulose acetate membrane $(0.22 \mu \mathrm{m})$. The viral inoculum was diluted with serum-free MEM, and $90 \mu \mathrm{L}$ was added to each well of 96-well monolayer culture of ST cells immediately followed by the addition of $10 \mu \mathrm{L}$ of bacterial supernatant so that the final viral titers were 1, 10,100 , and $1,000 \mathrm{TCID}_{50} / 0.1 \mathrm{ml}$. Quadruplicate wells were maintained for each concentration of the virus. Control cells with viral inoculum (1 to $1,000 \mathrm{TCID}_{50} /$ $0.1 \mathrm{ml}$ ) but without bacterial supernatant, with bacterial supernatant but without viral inoculum, and with serumfree MEM alone were also maintained. The plate was observed for CPE at 24, 48, and $72 \mathrm{~h}$, and the absence of CPE was regarded as presence of antiviral activity.

Antimicrobial activity assay

Antimicrobial activities of the bacterial isolates were tested for growth inhibition of 13 pathogenic microorganisms. The indicator strains were cultured overnight 


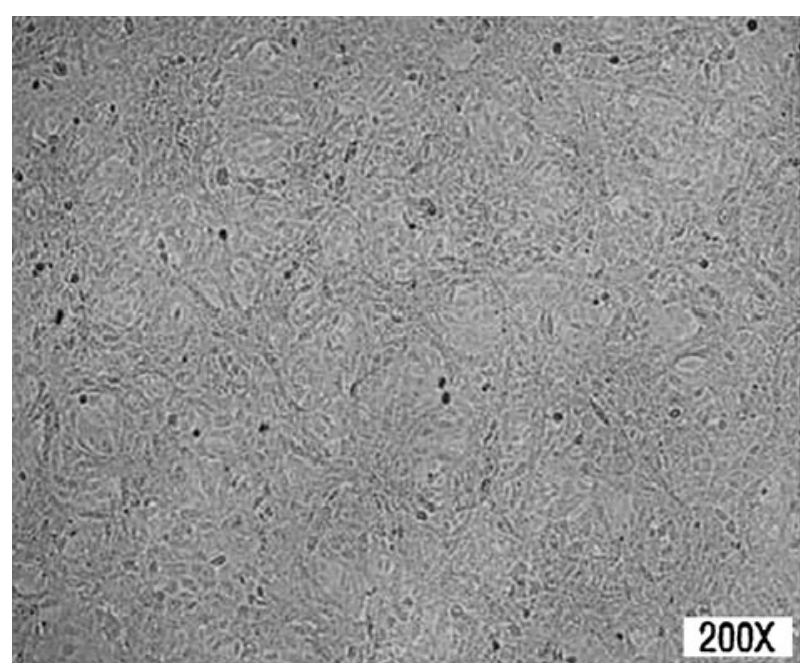

a) Control

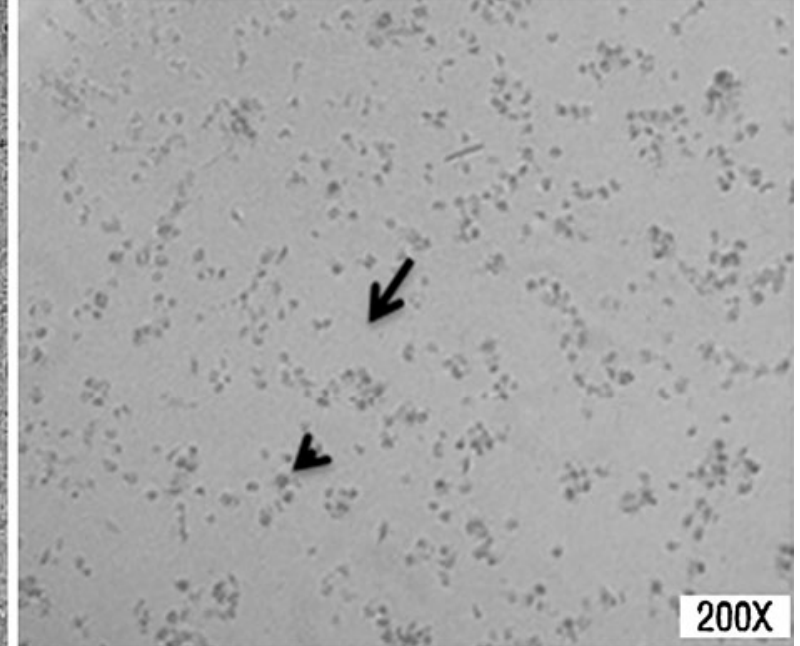

b) Infected

Fig. 1 Cytopathic effect of TGE corona virus in ST cell line. Note the degradation of monolayer (arrow) and morphological changes of cells (arrowhead). a Control, b infected

anaerobically in MRS broth, and $1 \mathrm{~mL}$ of each culture was spread over MRS agar media. Isolated strains, cultured overnight in MRS medium, was centrifuged at 12,000 rpm for $15 \mathrm{~min}$, and the supernatant was heated at $70^{\circ} \mathrm{C}$ for 5 min followed by vacuum concentration (Modulspin 40, Hanil R\&D, South Korea). From this, $30 \mu \mathrm{L}$ was used to impregnate the disks. After impregnation, the disks were positioned on the MRS plates, which were spread with the pathogenic microorganisms. Inhibitory circles emerging after incubation were measured.

Survival in synthetic gastric juice and porcine bile tolerance

To examine the ability of isolates to survive gastric conditions, overnight cultures were washed with phosphate-buffered saline ( $\mathrm{pH}$ 7.4) and adjusted to about $10^{8}$ to $10^{9} \mathrm{CFU} \mathrm{mL}^{-1}$ and resuspended in synthetic gastric juice $\left(3.5 \mathrm{~g} / \mathrm{L}\right.$ D-glucose, $2.05 \mathrm{~g} / \mathrm{L} \mathrm{NaCl}, 0.6 \mathrm{~g} / \mathrm{L} \mathrm{KH}_{2} \mathrm{PO}_{4}$, $0.11 \mathrm{~g} / \mathrm{L} \mathrm{CaCl}, 0.37 \mathrm{~g} / \mathrm{L} \mathrm{KCl}, 0.05 \mathrm{~g} / \mathrm{L}$ porcine bile (Sigma), $0.1 \mathrm{~g} / \mathrm{L}$ lysozyme, and $13.3 \mathrm{mg} / \mathrm{L}$ pepsin), and $\mathrm{pH}$ was adjusted to 2 using $\mathrm{HCl}$ and incubated anaerobically for $0 \mathrm{~min}, 30 \mathrm{~min}$, and $2 \mathrm{~h}$ at $37^{\circ} \mathrm{C}$ (Casey et al. 2004). Samples were withdrawn at regular intervals, serially diluted in PBS and enumerated on MRS agar. For assessing the bile tolerance, porcine bile was added to MRS plates at concentrations of $0.3,0.5,1.0,2.0$, and $5.0 \%(w / v)$; these plates were incubated under anaerobic conditions for $24 \mathrm{~h}$ prior to use. Overnight cultures of selected isolates were streaked with an inoculating loop onto the surface of triplicate individual plates and incubated anaerobically for $72 \mathrm{~h}$ at $37^{\circ} \mathrm{C}$, after which the plates were examined for bacterial growth.
Antibiotic susceptibility

Antibiotic susceptibility of the selected strains was tested against 11 antibiotics using BBL Sensi-Disc $(8 \mathrm{~mm})$. Bacterial strains were cultured in MRS culture broth at $37^{\circ} \mathrm{C}$ for $18 \mathrm{~h}$ and smeared homogeneously on MRS culture plates. Antibiotic disks were placed on the plates and incubated for $24 \mathrm{~h}$ at $37^{\circ} \mathrm{C}$. The inhibitory circles emerging after $24 \mathrm{~h}$ of anaerobic incubation were measured.

\section{Results}

Among the 310 bacterial isolates screened, two strains with high activity against TGE virus and enteric pathogens were selected and identified. Both the strains were Gram positive and could grow in both aerobic and anaerobic conditions without the formation of spores, and had no motility. Their optimal growth temperature ranged from $30^{\circ} \mathrm{C}$ to $37^{\circ} \mathrm{C}$. These strains neither generated gas and indole, nor showed neither hemolysis and nor reduced nitric acid. Both the strains were tolerant to $5 \%$ bile acid. Based on the phenotypic and genotypic characterization, and subsequent $16 \mathrm{Sr}$ DNA sequence analysis, the Probio38 and 37 showed $99 \%$ similarity with $L$. plantarum and Lactobacillus salivarius, respectively. They were identified as L. plantarum Probio-38 and L. salivarius Probio-37 with GenBank nucleotide accession numbers GU357499 and GU357500, respectively. Probio-38 and 37 were also deposited in the Korean Culture Center of Microorganisms under respective accession no. KCCM 10329 and KCCM 
Table 1 Antiviral activity of the isolates against porcine rotavirus as measured by the absence of CPE

\begin{tabular}{lllll}
\hline $\begin{array}{l}\text { Time of } \\
\text { incubation }\end{array}$ & \multicolumn{2}{l}{ Viral titer } & & \\
\cline { 2 - 5 } & 1,000 & 100 & 10 & 1 \\
& $\operatorname{TCID}_{50}$ & $\operatorname{TCID}_{50}$ & $\operatorname{TCID}_{50}$ & TCID $_{50}$ \\
\hline $24 \mathrm{~h}$ & - & - & - & - \\
$48 \mathrm{~h}$ & - & - & - & - \\
$72 \mathrm{~h}$ & + & \pm & - & - \\
\hline
\end{tabular}

10328 in accordance with the terms and provisions of the Budapest Treaty.

Only the cells treated with supernatants of the isolates Probio-38 and 37 were observed without any CPE after $48 \mathrm{~h}$ in all the concentrations of virus tested. At $72 \mathrm{~h}$, antiviral activity was only observed in 1-10 TCID $_{50}$ / $0.1 \mathrm{~mL}$ as evidenced by the absence of CPE (Table 1). CPE was observed in control cells with viral inoculum but without bacterial supernatant from $24 \mathrm{~h}$ onwards. Control cells with only bacterial supernatant were similar to control cells in serum-free MEM. They also inhibited the 13 pathogenic microorganisms tested as shown in Table 2 . The ability of growth inhibition against pathogenic bacteria was within an inhibitory circle diameter of 11-21 mm. Both the strains exhibited very high inhibition against $E$. coli KCTC 2441, Salmonella enteritidis kim sp14, Shigella flexneri KCTC 2008, Salmonella gallinarum, Salmonella typhimurium, and Citrobacter freundii KCTC 2006.

L. salivarius Probio-37 showed higher survival $(4.5 \times$ $10^{5} \mathrm{CFU} / \mathrm{mL}$ ) in acid condition than L. Plantarum Probio$38\left(3.8 \times 10^{5} \mathrm{CFU} / \mathrm{mL}\right)$, while the initial cell numbers were

Table 2 Antimicrobial activity of the isolates against pathogenic bacteria

\begin{tabular}{lcc}
\hline Indicator strains & \multicolumn{2}{l}{$\begin{array}{l}\text { Inhibitory activity } \\
\text { (diameter, mm) }\end{array}$} \\
\cline { 2 - 3 } & Probio-38 & Probio-37 \\
\hline Escherichia coli KCTC 2441 & 20 & 20 \\
Escherichia coli KCTC 2571 & 16 & 16 \\
Klebsiella pneumoniae KCTC 2208 & 15 & 18 \\
Staphylococcus aureus KCTC 1621 & 11 & 14 \\
Staphylococcus epidermis KCTC 1917 & 11 & 11 \\
Salmonella enteritidis kim sp14 & 20 & 21 \\
Shigella flexneri KCTC 2008 & 20 & 20 \\
Salmonella gallinarum & 21 & 21 \\
Enterobacter cloacae KCTC 2361 & 15 & 16 \\
Enterococcus lactis KCTC 1913 & 11 & 11 \\
Salmonella typhimurium & 19 & 20 \\
Citrobacter freundii KCTC 2006 & 19 & 21 \\
Bacillus subtilis KCTC 1021 & 11 & 12 \\
\hline
\end{tabular}

$2.5 \times 10^{8}$ and $2.7 \times 10^{8} \mathrm{CFU} / \mathrm{mL}$, respectively. Both the strains showed the maximum resistance at $5.0 \%$ and formed cloudy zones of precipitate in the growth media by producing bile salt hydrolase (Dashkevicz and Feighner 1989). The antibiotic sensitivity assay showed that both the strains exhibited resistance to broadly used antibiotics (Table 3). However, L. plantarum Probio-38 was highly sensitive to ampicillin, carbencillin, and erythromycin, whereas $L$. salivarius was also sensitive to cephalothin along with other three antibiotics.

\section{Discussion}

In the present study, to screen out potent probiotic strains from porcine gastrointestinal tract, we could select $L$. plantarum Probio-38 and L. salivarius Probio37 as potent probiotic strains. The antiviral effect and the actual mechanisms behind the activity of probiotics have not been studied much. Maragkoudakis et al. (2010) reported the potential antiviral activity of LAB using animal and human intestinal, and macrophage cell line models of non-tumor origin, and the various strains tested were found to exhibit moderate to complete monolayer protection against viral RV or TGEV disruption; the highest protection effects being recorded with the known probiotics Lactobacillus rhamnosus GG and Lactobacillus casei Shirota against both RV and TGEV. To the best of our knowledge, this is the first reported antiviral activity of $L$. plantarum and $L$. salivarius strains against TGE coronavirus.

An ideal probiotic bacterium must survive the harsh environments in the stomach having low $\mathrm{pH}$ and in the intestinal tract containing bile acids. Because of the bile tolerance, both the strains can grow and survive in the upper small intestine, where bile salt hydrolase activity of

Table 3 Antibiotic sensitivity of the isolates

\begin{tabular}{|c|c|c|}
\hline \multirow[t]{2}{*}{ Antibiotics (BBL Sensi-Disc, 6mm) } & \multicolumn{2}{|c|}{ Clear zone diameter $(\mathrm{mm})$} \\
\hline & Probio-38 & Probio-37 \\
\hline Tetracycline $(30 \mu \mathrm{g})$ & 8 & 8 \\
\hline Ampicillin $(10 \mu \mathrm{g})$ & 25 & 23 \\
\hline Gentamicin $(10 \mu \mathrm{g})$ & 8 & 9 \\
\hline Cephalothin $(30 \mu \mathrm{g})$ & 13 & 24 \\
\hline Sulfisoxazole $(25 \mu \mathrm{g})$ & 17 & 8 \\
\hline Carbenicillin $(100 \mu g)$ & 24 & 23 \\
\hline Streptomycin $(10 \mu \mathrm{g})$ & 8 & 8 \\
\hline Lincomycin $(2 \mu \mathrm{g})$ & 10 & 15 \\
\hline Neomycin $(30 \mu \mathrm{g})$ & 9 & 8 \\
\hline Pencillin $(10 \mu g)$ & 14 & 17 \\
\hline Erythromycin $(15 \mu g)$ & 32 & 31 \\
\hline
\end{tabular}


such lactobacilli may play a role in the enterohepatic cycle (De smet et al. 1995). The broad antimicrobial activities exhibited by both the strains are beneficial for the maintenance of intestinal microflora, which is one of the important properties expected from probiotic bacteria. Pascual et al. (1999) reported the great capability of $L$. salivarius CTC2197 to reduce $S$. enteritidis C-114 colonization in vivo, together with its ability to colonize the gastrointestinal tract of chicken after a single inclusion in the feed mixture. Angelis et al. (2006) selected many potential probiotic lactobacilli from pig feces to be used as additives in pelleted feeding. L. plantarum have been reported to possess excellent probiotic properties (Cebeci and Gurakan 2003), and Wullt et al. (2003) reported L. plantarum 299v for the treatment of recurrent Clostridium difficileassociated diarrhea. In the genus Lactobacillus, several bacteriocins have been partially purified and characterized from strains of $L$. acidophilus, Lactobacillus brevis, $L$. casei, Lactobacillus gasseri, Lactobacillus helveticus, $L$. plantarum, and Lactobacillus sakae (Klaenhammer 1993). Corr et al. (2007) reported that L. salivarius UCC118 tractable probiotic strain of human origin produces a bacteriocin in vivo that can significantly protect mice against infection with the invasive food borne pathogen Listeria monocytogenes. Further studies are required to determine on the bacteriocin production by the present strains to differentiate them from other bacteriocins described previously.

Antibiotic resistance has become a serious problem in treatment of infections caused by a variety of microorganisms due to the indiscriminate use of antibiotica in human and veterinary medicine, as well as in animal growth promoters (Mattila-Sandholm et al. 1999). The present results suggest that both the strains, as probiotics, could be able to colonize in the gastrointestinal tract in spite of antibiotic treatments. Probiotic feeding may represent an important antibiotic alternative therapy for animal and human subjects to prevent the enteropathogen infections. This is particularly important in the case of piglets, where the large use of antibiotics to prevent their frequent intestinal infections may have serious consequences on human health, due to the possible presence of antibioticresistant bacteria in pig food products and in animal wastecontaminated environments (Smith et al. 2002). The results of the present study indicates that both the isolated strains Probio- 38 and 37 with their $\mathrm{pH}$ and bile tolerance, activity against enteric pathogens, and TGE coronavirus and with antibiotic resistance are ideal probiotic candidates for animal application after the proper in vivo experiments.

Acknowledgment National Veterinary Research and Quarantine Service, Ministry for food, Agriculture, Forestry and Fisheries, Republic of Korea is acknowledged for supplying the virus and cell lines for the experiment.

\section{References}

Angelis M. D. Siragusa S. Berloco M. Caputo L. Settanni L. Alfonsi G. Amerio M. Grandi A. Ragni A. Gobbetti M. 2006. Selection of potential probiotic lactobacilli from pig feces to be used as additives in pelleted feeding. Research in Microbiology 157, 792-801.

Casey P. G. Casey G. D. Gardiner G. E. Tangney M. Stanton C. Ross R. P. Hill C. Fitzgerald G. F. 2004. Isolation and characterization of ant-salmonella lactic acid bacteria from the porcine gastrointestinal tract. Letters in Applied Microbiology 39, 431-438.

Cavanagh D. Brian D. A. Britton P. Enjuanes L. Horzinek M. C. Lai M.M.C. Laude H. Plagemann P. G. W. Siddell S. Spaan W. Talbot P. J. 1997. Nidovirales: a new order comprising Coronaviridae and Arteriviridae. Archives of Virology 142, 629-635.

Cebeci A. Gurakan C. 2003. Properties of potential probiotic Lactobacillus plantarum strains. Food Microbiology 20, 511-518.

Corr S. C. LinY. Riedel C. U. O’Toole P. V. Hill C. Gahan, C. G. M. 2007. Bacteriocin production as a mechanism for the anti-infective activity of Lactobacillus salivarius UCC118. Proceedings of the National Academy of Sciences 104, 7617-7621.

Dashkevicz M. P. Feighner S. D. 1989. Development of a differential medium for bile salt hydrolase-active Lactobacillus spp. Applied and Environmental Microbiology 55, 11-16.

De smet I. van Hoorde L. Vande Woestyne M. Christiaens H. Verstrate W. 1995. Significance of bile-salt hydrolytic activities of lactobacilli. Journal of Applied Bacteriology 79, 292-301.

Drago L. Gismondo M. R. Lombardi A. De Haen C. Gozzini L. 1997. Inhibition of in vitro growth of enteropathogens by new Lactobacillus isolates of human intestinal origin. FEMS Microbiology Letters 153, 455-463.

Enjuanes L. Smerdou C. Castilla J. Anton I. M. Torres J. M. Sola I. Golvano J. Sanchez J. M. Pintado B. 1995. Development of protection against coronavirus induced diseases. Advances in Experimental Medicine and Biology 380, 197-211.

Enjuanes L. Van der Zeijst B. A. M. 1995. Molecular basis of transmissible gastroenteritis coronavirus epidemiology. In: S. G. Siddell (Editor). The Coronaviridae. Plenum Press, New York. pp. 337-376.

Giang H. H. Viet T. Q. Ogle B. Lindberg J. E. 2010. Growth performance, digestibility, gut environment and health status in weaned piglets fed a diet supplemented with potentially probiotic complexes of lactic acid bacteria. Livestock Science 129, 95-103.

Jacobson M. Hard af Segerstad. C. Gunnarsson A. Fellstrom C. de Verdier Klingenberg K. Wallgren P. Jensen-Waern M. 2003. Diarrhoea in the growing pig - a comparison of clinical, morphological and microbial findings between animals from good and poor performance herds. Research in Veterinary Science 74, 163-169.

Klaenhammer T. R. 1993. Genetics of bacteriocins produced by lactic acid bacteria. FEMS Microbiology Reviews 12, 39-86.

Kritas S. K. Morrison R. B. 2007. Effect of orally administered Lactobacillus casei on porcine reproductive and respiratory syndrome (PRRS) virus vaccination in pigs. Veterinary Microbiology 119, 248-255.

Mangell P. Nejdfors P. Wang M. Ahrne S. Westrom B. Thorlacius H. Jeppsson B. 2002. Lactobacillus plantarum 299v inhibits Escherichia coli-induced intestinal permeability. Digestive Diseases and Sciences 47, 511-516.

Maragkoudakis P.A. Chingwaru W. Gradisnik L. Tsakalidou E. Cencic A. 2010. Lactic acid bacteria efficiently protect human and animal intestinal epithelial and immune cells from enteric virus infection. International Journal of Food Microbiology. doi:10.1016/j.ijfoodmicro.2009.12.024 (In Press).

Mattila-Sandholm T. Matto J. Saarela M. 1999. Lactic acid bacteria with health claims-interactions and interference with gastrointestinal flora. International Diary Journal 9, 25-35. 
Moxley R. A. Duhamel G. E. 1999. Comparative pathology of bacterial enteric diseases of swine. Advances in Experimental Medicine and Biology 473, 83-101.

Ouwehand A. C. Isolauri E. Salminen S. 2004. The role of the intestinal microflora for the development of the immune system in early childhood. European Journal of Nutrition 41, I32-I37.

Pascual M. Hugas M. Badiola J. I. Monfort J. M. Garriga M. 1999. Lactobacillus salivarius CTC2197 prevents Salmonella enteritidis colonization in chickens. Applied and Environmental Microbiology 65, 4981-4986.

Pritchard G. C. 1987. Transmissible gastroenteritis in endemically infected breeding herds of pigs in East Anglia, 1981-1985. Veterinary Record 120, 226-230.

Reed L. J. Muench H. 1938. A simple method of estimating fifty percent endpoints. American Journal of Hygiene 27, 493- 497.

Smith D. L. Harris A. D. Johnson J. A. Silbergeld E. K. Morris G. M. 2002. Animal antibiotic use has an early but important impact on the emergence of antibiotic resistance in human commensal bacteria. Proceedings of the National Academy of Science 99, 6434-6439.

Van Niel C. W. Feudtner C. Garrison M. M. Christakis D. A. 2002. Lactobacillus therapy for acute infectious diarrhea in children: A meta- analysis. Pediatrics 109, 678-684.

Wullt M. Marie-Louise Johansson Hagsla M-L.J. Odenholt I. 2003. Lactobacillus plantarum $299 \mathrm{v}$ for the Treatment of recurrent Clostridium difficile-associated diarrhoea: A double-blind, placebo-controlled trial. Scandinavian Journal of Infectious Diseases 35, 365-367.

Yoon J. H. Lee S. T. Park Y. H. 1998. Inter and intraspecific phylogenetic analysis of the genus Nocardioides and related taxa based on $16 \mathrm{~S}$ rDNA sequences. International Journal of Systematic Bacteriology 48, 187-194.

Zhang W. Azevedo M. S. P. Wen K. Gonzalez A. Saif L. J. Li G. Yousef A. E. Yuan L. 2008. Probiotic Lactobacillus acidophilus enhances the immunogenicity of an oral rotavirus vaccine in gnotobiotic pigs. Vaccine 26, 3655-3611. 